\title{
Review
}

\section{Fibre optic intravascular measurements of blood flow: A review}

\author{
Eleanor C. Mackle ${ }^{a}$, Joanna M. Coote ${ }^{a}$, Elizabeth Carr ${ }^{a}$, Callum D. Little ${ }^{a, b}$, Gijs van Soest ${ }^{c}$, \\ Adrien E. Desjardins ${ }^{\mathrm{a}, *}$ \\ ${ }^{a}$ Wellcome/EPSRC Centre for Interventional and Surgical Sciences, University College London, London, UK and Department of Medical Physics and Biomedical \\ Engineering, University College London, London, UK \\ ${ }^{\mathrm{b}}$ Imperial College Healthcare NHS Foundation Trust, UK \\ ' Erasmus Medical Center, Ee-2302, PO Box 2040, 3000 CA, Rotterdam, The Netherlands
}

\section{A R T I C L E I N F O}

\section{Article history:}

Received 17 June 2021

Received in revised form 21 September 2021

Accepted 5 October 2021

Available online 8 October 2021

\section{Keywords:}

Blood flow

Intravascular measurement

Coronary physiology

\begin{abstract}
A B S T R A C T
Fibre optic sensors are well suited to measuring fluid flow in many contexts, and recently there has been burgeoning interest in their application to direct, invasive measurement of blood flow within human vasculature. Depending on the sensing method used and assumptions made, these intravascular measurements of blood flow can provide information about local blood velocity, volumetric flow, and flowderived parameters. Fibre optic sensors can be readily integrated into medical devices, which are positioned into arteries and veins to obtain measurements that are inaccessible or cumbersome using non-invasive imaging modalities. Measurements of flow within coronary arteries is a particularly promising application of fibre optic sensing; recent studies have demonstrated the clinical utility of certain flow-based parameters, such as the coronary flow reserve (CFR) and the index of microcirculatory resistance (IMR). In this review, research and development of fibre optic flow sensors relevant to intravascular flow measurements are reviewed, with a particular focus on biomedical clinical translation.
\end{abstract}

(c) 2021 The Authors. Published by Elsevier B.V.

\section{Contents}

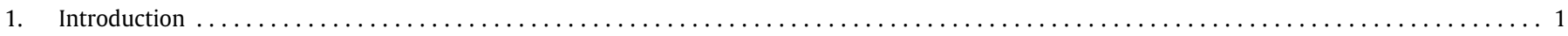

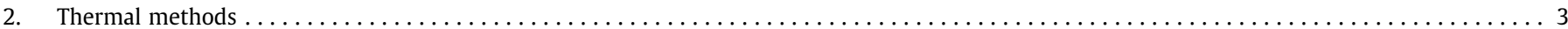

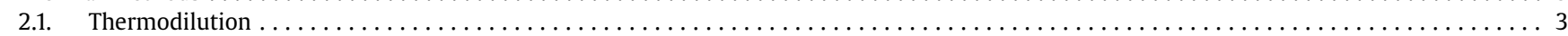

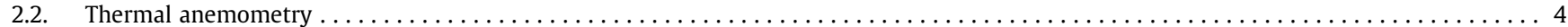

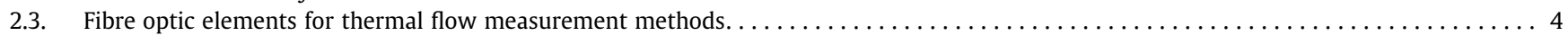

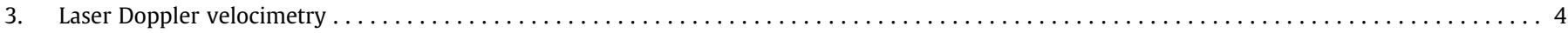

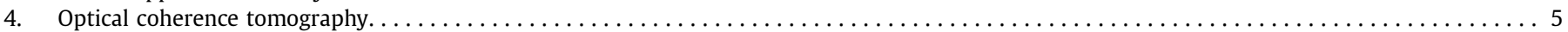

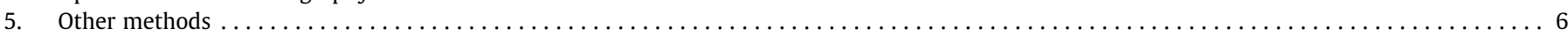

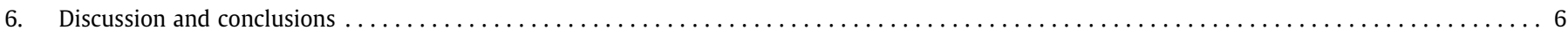

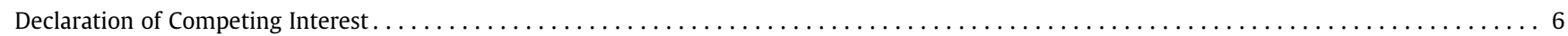

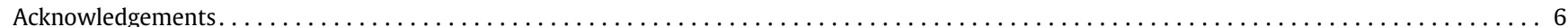

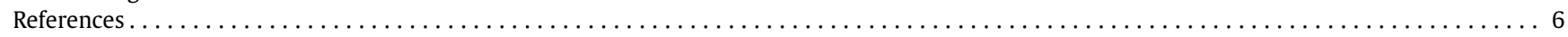

\section{Introduction}

Accurate measurements of blood flow from within arteries and veins are of significant interest in many clinical contexts. Coronary flow is a key parameter in assessing myocardial physiology, and so

\footnotetext{
* Corresponding author.

E-mail address: a.desjardins@ucl.ac.uk (A.E. Desjardins).
}

interventional cardiology is a prominent application space for intravascular flow measurements. These measurements are performed in the coronary arteries to assess the functional severity of stenoses, and to test the response of the downstream microcirculation to increases in cardiac demand [1]. Intravascular flow measurements have also been performed in the brain to assess abnormal vessel geometries such as arteriovenous malformations [2] and aneurysms [3], in the kidney to detect renal artery stenoses [4], and as part of a 


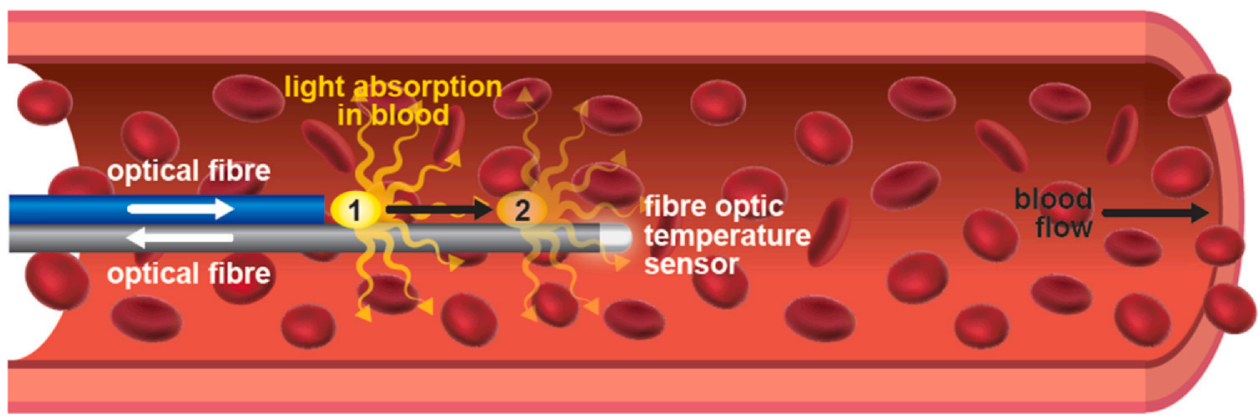

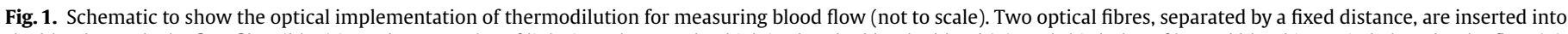

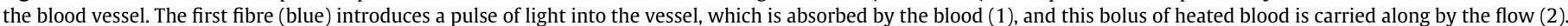

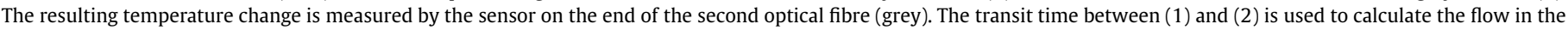
vessel.

procedure to restore blood flow in the liver using a transjugular intrahepatic portosystemic shunt (TIPS) [5].

The term 'blood flow' has been used to refer to many different quantities, with varying levels of complexity. For instance, it can refer to volumetric flow, or the maximum speed of red blood cells within a measurement volume. These quantities can be time-resolved within a cardiac cycle or time-averaged and depending on the measurement principle there may be information about the flow direction. Within complex vessel geometries and in the presence of pathologies such as arteriovenous malformations, one can expect correspondingly complex flow patterns. Ultimately, red blood cells provide a granularity to the definitions of blood flow that is prominent at the level of the capillary bed. With blood flow measurements, it is typically the red blood cells that are of interest, owing to their oxygen-carrying capacity, although other constituents of blood may be relevant in specific applications.

Whilst arterial and venous blood flow can be measured non-invasively, current imaging modalities have limitations that preclude their routine clinical use in certain applications. Positron Emission Tomography (PET) [6] is often taken as a "gold standard" technique for quantifying blood flow. However, a radioactive tracer must be administered to the patient, and scan times are too long for acute interventions. Magnetic resonance imaging (MRI) [7-9] is used with increasing frequency for measuring blood flow; however, the spatial and temporal resolutions are often incompatible with measurements from coronary arteries, and the long procedure times are not suitable for routine clinical workflow. External Doppler ultrasound imaging [10] is widely used to detect and measure flow from superficial vessels, but it is challenging to visualise coronary arteries, given their depth, small size, and the limited views between ribs. Intravascular flow measurements are, therefore, of critical importance in many settings.

In clinical practice, indirect intravascular flow measurements are performed using sensors integrated into guidewires and microcatheters [11]. The ratio between distal and aortic pressure in coronary arteries at maximum hyperaemia (pharmacologically induced maximal blood flow, which is used as a proxy for the physiological response to exercise), as quantified by the fractional flow reserve (FFR), can be used effectively to assess the functional impact of a stenosis in an epicardial artery, which determines the treatment pathway. FFR-guided percutaneous coronary interventions ( $\mathrm{PCI}$ ) have been shown to reduce the occurrence of future revascularisation procedures [12], and lesions with an FFR greater than 0.8 can be safely deferred for medical management rather than PCI [13]. However, using a pressure ratio as a surrogate for a direct flow measurement is subject to a number of assumptions about the venous pressure and the microvascular resistance [14]; FFR can fail to stratify risk accurately and can yield false positives depending on local physiology, sensor drift, and deep engagement of the guiding catheter (ventricularisation) [15-18].

Direct intravascular measurements of coronary blood flow have implications for therapeutic options in patients with microvascular dysfunction. Minimally invasive devices with integrated temperature sensors are used to obtain clinical flow-derived metrics such as the coronary flow reserve (CFR) [19,20] and the index of microcirculatory resistance (IMR) [21,22]. The CFR index is defined as the ratio of hyperaemic blood flow through a coronary artery and the baseline (non-hyperaemic) blood flow at rest in a coronary artery. The IMR index is the ratio of the pressure and a flow parameter to obtain a measure of resistance; this flow parameter is calculated as the inverse of the hyperaemic mean transit time of blood. The CFR relates to both an epicardial coronary artery and the downstream microvasculature, whereas the IMR is specific to the downstream microvasculature [22]. These indices may be important to develop novel therapeutic options and could form part of the criteria required to initiate these treatments for patients. Additionally, they can be used to exclude other diagnoses such as coronary artery spasm [23]. Devices with Doppler ultrasound sensors, which

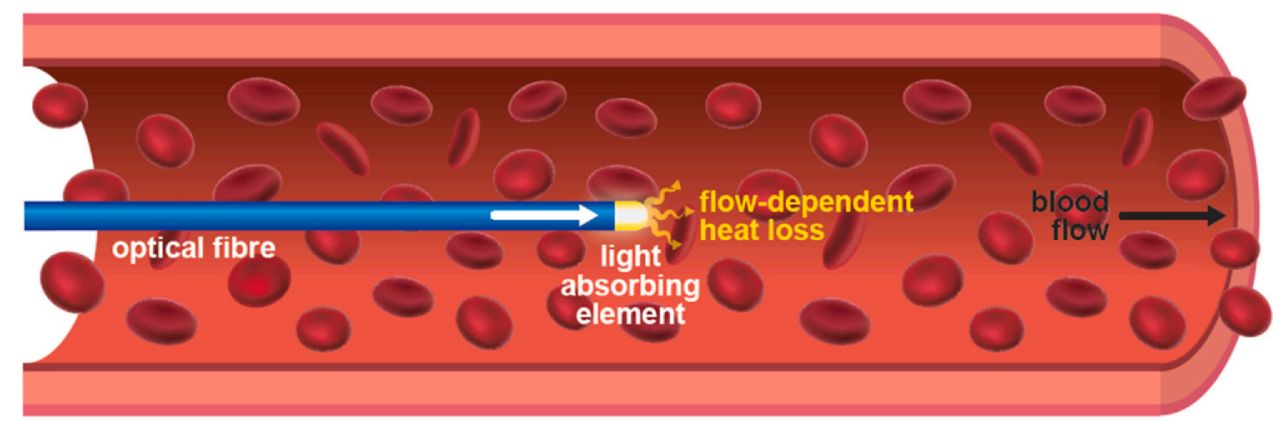

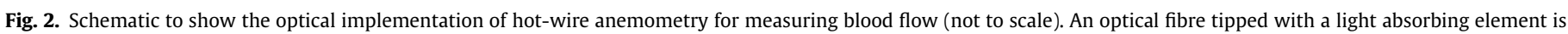
inserted into the blood vessel. Flow dependent heat loss at the fibre tip is then used to calculate blood flow in the vessel. 


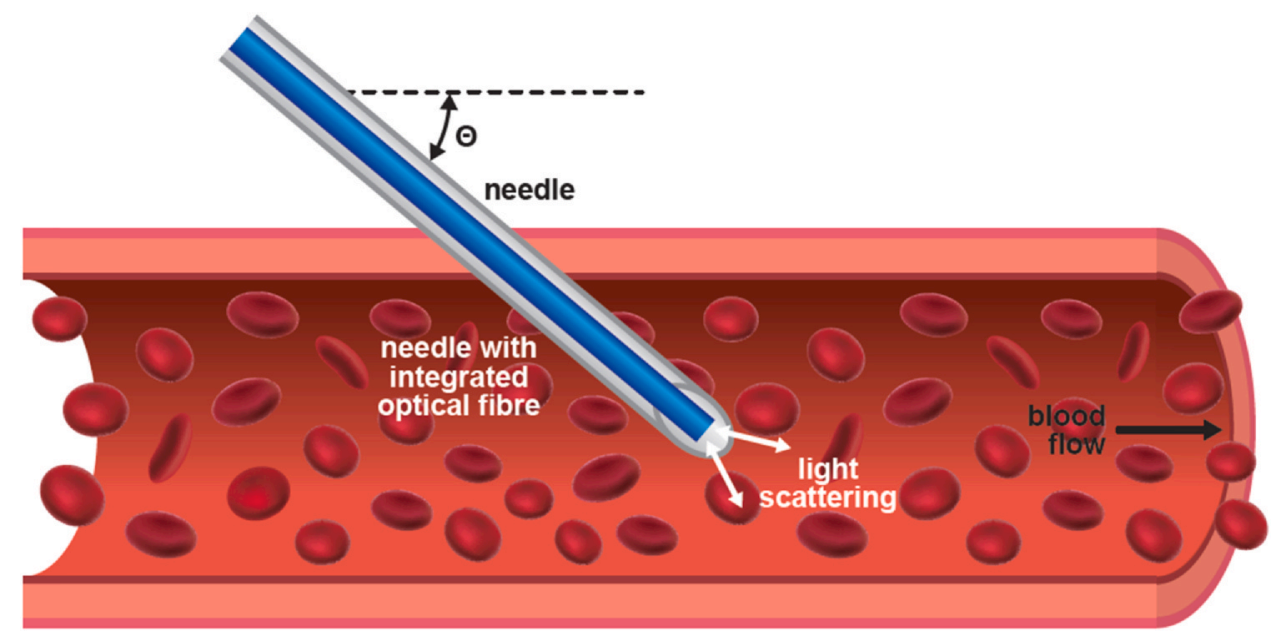

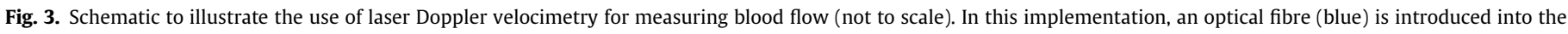

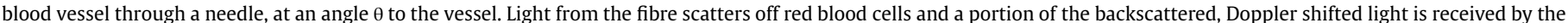

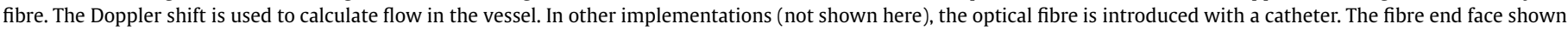

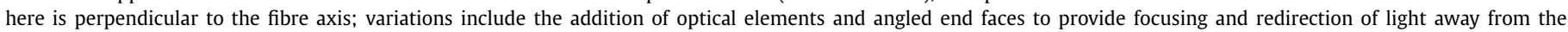
longitudinal axis of the device.

measure mean and peak ultrasound frequency shifts resulting from the movement of red blood cells, can also be used to obtain CFR measurements [24].

Intravascular flow sensing presents a unique set of challenges, as arterial flow has significant temporal variations across the cardiac cycle; it is higher in diastole than in systole and varies between arteries. For example, using Doppler transthoracic echocardiography, Sharif et al. reported mean peak diastolic and systolic velocities in the left anterior descending coronary of $41 \mathrm{~cm} / \mathrm{s}$ and $18 \mathrm{~cm} / \mathrm{s}$, respectively, in the absence of apparent stenoses [25]. Conversion from velocities to volumetric flow rates can be performed using estimates of the cross-sectional arterial area. Blood flow can vary significantly under different physiological conditions. Using intracoronary Doppler ultrasound, Wieneke et al. [26] reported mean volumetric flow rates, dependent on the coronary artery, that varied between $50 \mathrm{~mL} /$ min at rest, and up to peak flow rates of $250 \mathrm{~mL} / \mathrm{min}$ at maximum hyperaemia [26]. Intravascular flow also varies spatially; in laminar flow, the flow velocity is greatest in the centre and falls parabolically to the vessel walls. Deviations from laminar flow profiles can arise from complex geometries (such as bifurcations or aneurysms) and the presence of other devices such as guidewires and stents [27,28]. Depending on the intravascular flow sensing method, pronounced motion of the heart and arteries can be significant confounding factors $[27,28]$. Corrections to accommodate for the presence of the measurement device may be warranted in certain contexts [27].

Optical fibres have many advantages that have made them suitable for clinical applications [29]. For instance, relative to electronic sensors, they can confer immunity to electromagnetic interference, compatibility with MRI [30-33], and multiplexing capabilities [34]. With small lateral dimensions, flexibility, and biocompatibility of standard coatings such as polyimide, they can often be readily integrated into intravascular medical devices. Coronary physiology is already assessed in clinical practice using optical pressure sensors from a number of manufacturers (Boston Scientific, Marlborough, USA; ACIST Medical Systems, Minnesota, USA; OpSens Medical, Québec, Canada), which demonstrates that optical techniques can be used for intravascular sensing. However, as pressure measurements are only proxies for direct flow measurements, it would be beneficial to achieve direct, intravascular quantification of blood flow using optical techniques.

In this narrative review, we present fibre optic methods for performing intravascular flow measurements. Some of these methods have already been explored in biomedical contexts; others have shown promise based on their use in industrial applications. For each method, we present the underlying principle, advantages and limitations, and progress with clinical translation.

\section{Thermal methods}

\subsection{Thermodilution}

Thermodilution has its origins in indicator dilution techniques, which have been used to measure the time taken for blood to circulate between two different locations in the vascular system. As early as 1761, Haller injected coloured liquids into the vena cava of an animal immediately post-mortem, to compare circulation times in inflated and collapsed lungs [35]. Currently, thermodilution is applied to measure cardiac output and blood flow within coronary arteries [36,37].

In clinical practice, thermodilution involves injecting an indicator fluid (usually saline or X-ray contrast agents), which is typically cooler than body temperature. This indicator is transported with the blood, and the resulting downstream temperature change is detected by a sensor in an intravascular device, such as a catheter or guidewire. The indicator fluid can be injected at a constant rate for a fixed time interval, with a syringe pump (continuous thermodilution) [38-40], or in a bolus with a much shorter duration, with a rapid manual injection (instantaneous thermodilution or 'time of flight' thermodilution) [41,42]. In continuous thermodilution, the volumetric blood flow rate is calculated using the known temperature of the indicator fluid at the time of injection and the measured temperature change of the blood [43-45]. With instantaneous thermodilution, flow parameters can be obtained using the measured transit times of the injected cool fluid travelling from the injection site to the detection site $[41,42]$ (Fig. 1). When manual fluid bolus injections are performed for instantaneous thermodilution, repeated measurements and manual removal of outliers are often required due to variability of the resulting thermal measurements $[46,47]$.

A recently developed fibre optic implementation of thermodilution involves delivering light pulses into the blood stream in place of manual fluid bolus injections. This light is absorbed by chromophores such as haemoglobin or water, and the transit time taken for the bolus of "thermally tagged" blood to propagate to the 


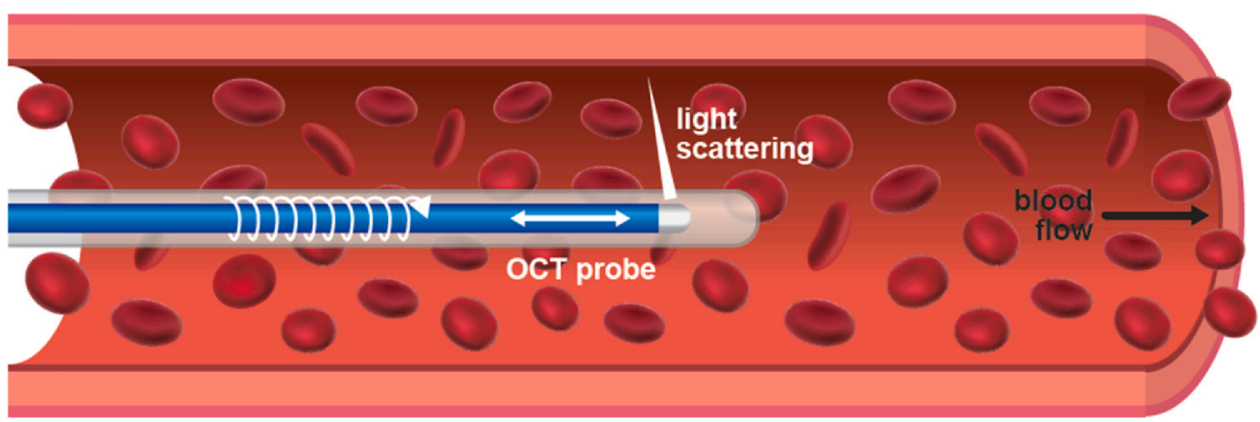

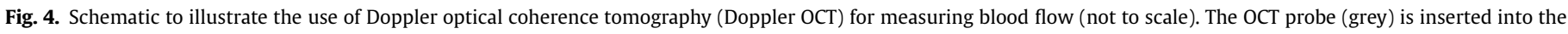

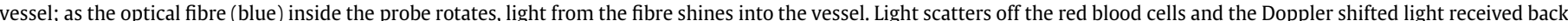

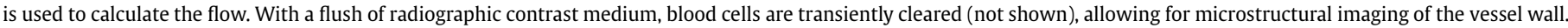

temperature sensor is measured [48]. In a study by Carr et al., this implementation was tested with a phantom model, using blood mimicking fluid and anatomical human flow rates.

\subsection{Thermal anemometry}

With thermal anemometry, heat is provided into a region within or immediately adjacent to the sensor, and this thermal energy is transferred out of that region at a rate dependent on the fluid flow. Temperature measurements are performed within the sensor and calibrated to the rate of fluid flow. Fibre optic sensors that perform thermal measurements of intravascular flow typically comprise two components: one for effecting a temperature change and a second for measuring the temperature (Fig. 2).

Electronic implementations of thermal anemometry are wellestablished for measuring the flow rate of wind, and fluid through pipes [49-58]. They are often referred to as 'hot wire' anemometry; heat is deposited into a wire with an electrical current and the timedependent temperature of the wire is recorded. If current is held constant, the wire's temperature is directly related to the instantaneous flow rate. Alternatively, if the wire's temperature is held constant by an adjustable current, the instantaneous flow is directly related to the current [59]. Thermal anemometry was implemented for intravascular measurements by van der Horst et al., using electronic temperature sensors within pressure-sensing guidewires, in combination with a constant-temperature electronic heating scheme $[60,61]$.

Ruiz-Vargas et al. proposed a method for performing anemometric fibre-optic intravascular flow measurements of pulsatile blood, using laser diode light to provide heat into the blood via absorption, and with temperature measurements performed optically [62]. Testing was performed with benchtop flow rigs.

\subsection{Fibre optic elements for thermal flow measurement methods}

Fibre optic temperature sensors used for thermodilution and thermal anemometry can be classified as either intrinsic or extrinsic [63]. With the former, sensing is performed within optical fibres themselves; with the latter, sensing is performed using an element that is distinct from the optical fibre [48]. Detailed reviews on fibre optic temperature sensors have been provided by Talataisong et al., Schena et al. and Roriz et al. [64-66].

To date, Fibre Bragg Gratings and Fabry-Pérot cavities are two examples of intrinsic and extrinsic fibre optic temperature sensor types, respectively, which have shown particular promise with flow measurements. Fibre Bragg gratings (FBGs) are used for industrial fluid flow measurements [67-71] and were recently used for intravascular flow sensing [62]. As intrinsic sensors, FBGs can be compact in the lateral dimension (a standard cladding diameter is $125 \mu \mathrm{m}$ ), which is often advantageous for integration into minimally invasive cardiovascular devices. Detailed literature exists on the design and function of FBGs [72-74]. A limitation of FBG sensors is that they are responsive to both temperature and strain [75-79]; the latter can be a confounding factor that may be prominent within physiological environments, particularly within a beating heart. Fabry-Pérot interferometers (FPIs) are often more compact in length (as measured along the fibre axis), which can lead to less crosssensitivity to strain. Subsequently, there have been many examples within the literature of their use as fibre optic flow sensors, including for water and gas flow [80-82]. Hybrid approaches involving FBGs and FPIs have been used for flow sensing [83,84].

For optical deposition of heat to perform fibre optic thermal measurements of flow, several schemes been proposed. For thermodilution, light can be provided to the flowing medium adjacent to the sensor by a bare optical fibre [62] and via a diffuser [48]. For thermal anemometry, light has been directed at absorbing materials external to the optical fibre including metallic coatings $[85,86]$, carbon nanotube coatings $[87,88]$ and semiconductor materials such as silicon [82,89], and internal to fibre such as cobalt dopants $[54,56,84]$.

\section{Laser Doppler velocimetry}

Laser Doppler Velocimetry (LDV), which is also known as laser Doppler anemometry, is a well-established principle for measuring flow [90]. When applied to vascular flow measurements, laser light is delivered into blood, and the Doppler shift of light backscattered from red blood cells is measured and used to calculate the velocity of the fluid (Fig. 3). This calculation involves the Doppler shift frequency, the wavelength of light used, and the refractive index of the fluid and the insertion angle [90]. The Doppler shifts are usually much smaller than the optical frequency, and so heterodyne detection is often used. Heterodyne-based LDV systems include "reference beam" and "Doppler difference" configurations [91]. With the former, only one beam is delivered into the blood; back-scattered light from this beam is mixed with a reference beam. The latter comprises two coherent incident beams, which cross over and scatter in the flow; the superposition of these two beams is then used to quantify the flow. The principle of self-mixing in a semiconductor laser diode through an optical fibre has also been used for LDV. Here, backscattered Doppler-shifted light is provided as feedback into the laser diode cavity, which modulates the intensity of the laser light [92-96].

In its early stages of development, LDV was used to measure blood flow in the retina [97] and superficial muscles [98,99], and from inside the body opened surgically [100]. However, attenuation of light in tissue presented challenges with obtaining signals from deeper vessels without surgically opening the body. Tanaka and Benedek [101] overcame this challenge with fibre optics; they exposed the femoral vein of a rabbit and used a needle to insert a 
$500 \mu \mathrm{m}$ diameter fibre directly into the vessel to make flow measurements. Refinements to this measurement paradigm were undertaken in a wide range of subsequent studies [102-104], which included deploying the sensor fibre via needles and micromanipulators [95,105-107]. In 2014, Tajikawa et al. showed that the velocity distribution of human, caprine and bovine blood could be measured very accurately with LDV [108]. Positioning a bare fibre into the blood stream can yield valuable feasibility data. Ultimately, however, tightly integrating the bare fibre into a medical device is essential to ensure compatibility with current clinical practice and to mitigate the risk of fibre breakage.

Arterial catheters, which are advanced along guidewires and typically inserted via the femoral or radial arteries, have been used as hosts for optical fibres for LDV measurements [109]. Kilpatrick et al. [110] used a catheter to advance an optical fibre into the coronary arteries of dogs, and Kajiya et al. developed a catheter type LDV system for clinical applications [106,107,111]. Sezerman et al. [112] and Kilpatrick et al. [113] developed LDV catheter-based systems [114] specifically for clinical use in coronary sinus, in the ventricles and atria [115], and epicardial large coronary vessels and epicardial small arteries [105,116-118] and veins [119,120].

Whilst LDV can be performed with a single, perpendicularly cleaved fibre to deliver and receive light, other configurations with more complexity can improve performance. Tanaka and Benedek [101] showed that polishing the fibre tip at a 45-degree angle improved measurement stability by directing light at blood flow along the side of the fibre. Scalise et al. also highlighted the importance of the cleave angle of the fibre tip [92]. Tajikawa et al. [121] used a convex lens tip at the distal end to mitigate reflections in the fibre tip. Kohri et al. [122] also used chemical etching to make a miniaturised fibre optic LDV system that they used for local velocity measurement of pulsatile human blood flow. Mito et al. [120], Kajiya et al. [116] and Ohba et al. [123] developed a dual fibre catheterbased system that used one fibre to introduce laser light into the blood stream, and another fibre to detect the backscattered light [124], with the aim of making more accurate measurements in disturbed flows than was possible with a single fibre.

Several challenges with LDV have been identified. First, laser light is prominently absorbed by blood, particularly with visible wavelengths, which significantly limits the sample volume [122]. Second, the systems can be sensitive to the confounding factors such as temperature and pressure [125]. Finally, LDV primarily measures the rate of motion of red blood cells rather than the whole blood flow rate [126]. The concentration of red blood cells is highest in the centre of the vessel where flow tends to be highest [127]; this spatial variation may give rise to spatial biases with flow estimation.

\section{Optical coherence tomography}

Optical coherence tomography (OCT) is an imaging modality that provides depth-resolved imaging in tissue. Intravascular OCT (IVOCT) is widely used in cardiology to perform endovascular visualisation of tissue microstructure and stent struts, as reviewed recently by Bouma et al. [128]. With IV-OCT, imaging is performed at the distal end of a catheter that delivers focused light into tissue. Backreflected light is depth-resolved interferometrically. Probes for performing IV-OCT typically comprise a single-mode fibre with a mirror and lens at the distal end for deflecting light off-axis through the vessel lumen and towards tissue. Rotational scanning is used to obtain 2D cross-sectional images and a helical scan pattern to obtain 3D images. For microstructural imaging of the vessel, blood is transiently cleared with an injection of saline or X-ray contrast via the microcatheter, as red blood cells are highly scattering. However, imaging in the presence of scattering particles such as red blood cells permits acquisition of a Doppler signal or quantification of signal fluctuations that relate to flow.
In Fourier-domain IV-OCT systems, the detected interference is resolved as a function of wavenumber, yielding an interferogram. In current clinical practice, IV-OCT is primarily used to provide structural contrast, which is obtained with the absolute value of the Fourier transform of the interferogram. However, the complex argument of the Fourier-transformed interferogram gives rise to a depth-resolved Doppler signal for measuring subtle changes in the position of light back-scatterers [129]. These changes in position can be processed to obtain cross-sectional images of blood flow (Fig. 4). Intravascular Doppler OCT (IV-DOCT) is in early stages of development as compared with conventional IV-OCT, but results have been very promising. Sun et al. assessed the feasibility of this technique with in vivo intraluminal blood flow measurement in a porcine carotid model [130]. Subsequent developments from this research group included enhanced signal processing by averaging over multiple sub-bands of the interferogram to increase the signal-to-noise ratio (SNR) [131], comparisons with computational fluid dynamics (CFD) [132], imaging of flow patterns around stent struts [133], and the use of graphics processor units for real-time processing [134]. Recently, three-dimensional morphological images and Doppler flow profiles of an entire coronary artery were achieved using a highspeed (1.5 MHz wavelength sweep rate) Fourier domain mode locked (FDML) laser [135].

As compared with other intravascular optical flow measurement techniques, IV-DOCT is currently the only one that has provided cross-sectional images of blood flow. This capability could prove advantageous to improve our understanding of irregular flow patterns in diseased blood vessels. With IV-DOCT, there are several challenges that give rise to artefacts and limit the SNR. Most importantly, full blood is too strongly attenuating to image across the artery, and multiple scattering destroys the phase relation between neighbouring A-scans on which IV-DOCT relies. Another complication is the degradation of Doppler signals by mechanical vibrations resulting from rotation of the optical components that focus light, by movements of the catheter sheath, and by non-uniform rotational distortion (NURD) that arise from variations in rotational speed. Different strategies have been used to mitigate the artefacts, including the use of semi-stable phase reference points [136] or use of a highly controllable distally driven micromotor catheter [137].

Speckle decorrelation is a technique for obtaining flow measurements from intravascular OCT that is complementary to IVDOCT. As OCT is based on coherent addition of waves, it gives rise to speckle. The speckle pattern observed across an image, which manifests as a random variation in image intensity, originates from the spatial distribution of light back-scatterers at the microscopic level. When these back scatterers are red blood cells and other constituents of blood, their spatial distribution changes in time with the presence of flow. The speckle decorrelation technique involves measuring spatially resolved temporal decorrelation of the OCT intensity signal and relating it to the blood flow speed. Recent studies have focused on improved understanding of this relationship and improved statistical estimations $[138,139]$, to provide a foundation for its future application to intravascular flow imaging.

For performing intravascular microstructural imaging, IV-OCT is complementary to intravascular ultrasound (IVUS). A similar complementarity may emerge between quantitative flow measurements performed with IV-DOCT and those with IVUS [140,141]. The slower pullback speeds of IVUS, as compared with those of OCT, are a disadvantage in terms of limiting the effects of cardiac motion for computational flow measurements [141]; however, IVUS does not require flushing, which can be advantageous in terms of covering greater distances with a pullback. The spatial resolution of OCT is higher than that of IVUS, which may be advantageous for resolving fine variations in flow within a vessel. Lumen delineation with IVUS and OCT has recently been used to obtain computational FFR estimates [141-144]. 


\section{Other methods}

Many sensing principles that are being developed for biomedicine originated from other application spaces [145]. In this section we consider several methods that hold promise for intravascular flow sensing in the future.

Distributed sensing methods based on Rayleigh scattering [146], Raman scattering [147] and Brillouin scattering [148] have been used for industrial flow measurements [149-152]. All three involve measuring changes to scattered light from inside optical fibres [153-155]; these changes can be localised at multiple locations using time domain reflectometry and analysis (OTDR/OTDA) [156]. Chen et al. created a distributed flow sensor that was based on Rayleigh scattering [157]. Wylie et al. created a hot wire anemometer based on Brillouin OTDA, and demonstrated its use for monitoring air flow [158]. Garcia-Ruiz et al. created a distributed optical fibre hot wire anemometer that allowed for continuous monitoring of wind speed over tens of kilometres, using chirped-pulse phase sensitive OTDR [159]. These examples suggest that the temperature sensitivity of Rayleigh, Raman, and Brillouin scattering, at multiple spatially resolved locations along a fibre, may find application in intravascular flow sensing with distributed anemometry. Other types of gratingbased sensors exist, apart from FBGs, but they are less common in the fibre optic flow sensing literature [160]. Caldas et al. used long period gratings (LPGs) to couple light into a fibre, where it could then be absorbed by an FBG [161]. Rao et al. demonstrated the use of two FBG-based temperature sensors for medical applications [162]. They use a thermodilution catheter for cardiac monitoring and suggest that it could be applied to in vivo applications; however, to the authors' knowledge, this step has not yet been taken. Biomedical applications of distributed sensing have also been considered. Tosi et al. used distributed thermal sensing to monitor ablation of tissue outside of the body [163]. The authors were able to achieve real time temperature measurements and a spatial resolution of $75 \mu \mathrm{m}$. Their method used multiple chirped FBGs, allowing sensing to occur at multiple points along a fibre length, using a 'quasi-distributed' technique similar to the one used by Willsch et al. [164]. These biomedical applications of distributed temperature sensing with FBGs lend weight to the future use of FBGs in intravascular fibre optic-based flow sensing.

Photoacoustic (PA) and all-optical ultrasound sensing could potentially be applied to intravascular flow measurements. With PA imaging, a pulse of light is provided to tissue and optical absorption gives rise to ultrasonic waves via the photoacoustic effect. Recently there has been significant interest in this modality to perform intravascular imaging with molecular contrast for pathologies in the vessel walls, such as lipid rich plaques [165]. Photoacoustic imaging performed from outside the body has been used to measure and image blood flow with different mechanisms including PA Doppler shifts [166,167], PA Doppler bandwidth broadening [168], the temperature dependence of the Grüneisen parameter [169], and field fluctuations [170]. With all-optical ultrasound imaging, pulsed light is provided to an engineered coating where it generates ultrasound, and reflections are received. This modality has recently been used to obtain pulse-echo ultrasound images within the heart and in arteries using all-optical transducers [171,172]. Using clinical learnings from the use of electronic Doppler flow wires in interventional cardiology (see, for instance, Claessen et al. [173] and recent innovations involving the use of modulated laser diodes [174]), there is potential for all-optical ultrasound sensing to be used to perform intravascular flow measurements. Fibre optic implementations of PA/all-optical ultrasound could prove to be well suited to multimodality sensing, allowing for both flow measurements and molecular or microstructural imaging.

Optical methods for directly visualising microcirculation might be applicable to intravascular flow measurements. As reviewed by
Ocak et al. [175] and Lal et al. [176], recent advances have allowed for direct visualisation of the red blood cells in the human body, for instance within the sublingual capillary bed. Fibre bundle implementations of these such as the one by Liu et al. [177] that are currently positioned outside the body could potentially be miniaturised and used to visualise the flow of red blood cells from within vessels.

\section{Discussion and conclusions}

With recent developments, fibre optic intravascular flow sensors have strong potential for clinical translation. This review highlighted fibre optic thermal methods, laser Doppler velocimetry, and intravascular Doppler OCT as methods that have been tested within realistic intravascular environments. Going forward, cross-fertilization of ideas between biomedical and industrial applications will lead to further refinements and cost-reductions of sensors, and the consoles that interrogate them. For these developments and ultimately for clinical training, vascular phantoms can be invaluable, and recently there have been many innovations in this space $[178,179]$.

The value of intravascular flow measurements for diagnosing coronary microvascular dysfunction, as complementary to pressurebased flow metrics such as FFR, is being increasingly appreciated. Across a wide range of applications, fibre optic blood flow sensors could play a prominent role. From a clinical translation standpoint, presenting actionable information about intravascular flow that is directly relevant to decision making is a key challenge. Meeting this challenge is likely to involve minimising the complexities of the sensor, the device, and the signal processing algorithms, whilst retaining sufficient information to convey the complexity of diverse pathologies. Clinical experience with FFR serves to illustrate that a single, validated threshold to direct interventional strategy can be an extremely powerful tool that is readily adopted by a clinical user base. A similar translational path can be anticipated for intravascular flow measurements, which could be invaluable for identifying and treating coronary microvascular dysfunction.

\section{Declaration of Competing Interest}

The authors declare the following financial interests/personal relationships which may be considered as potential competing interests: Adrien Desjardins is a Director of Echopoint Medical.

Jo Coote was previously a Consultant for Echopoint Medical Ltd.

\section{Acknowledgements}

The authors gratefully acknowledge insightful feedback from Dr. Malcolm Finlay (Barts Hearts Centre, St Bartholomew's Hospital, London, UK), and from the peer review process. Funding was provided by the National Institute for Health Research UCL Biomedical Research Centre and the Wellcome/EPSRC Centre for Interventional and Surgical Sciences (WEISS) (203145Z/16/Z; NS/A000050/1).

\section{References}

[1] V.R. Taqueti, M.F. Di Carli, Coronary microvascular disease pathogenic mechanisms and therapeutic options: JACC state-of-the-art review, J. Am. College Cardiol. 72 (2018) 2625-2641, https://doi.org/10.1016/j.jacc.2018.09.042

[2] G. Benndorf, S. Singel, G. Proest, W. Lanksch, R. Felix, The Doppler guide wire: clinical applications in neuroendovascular treatment, 1997.

[3] G. Benndorf, E. Wellnhofer, W. Lanksch, R. Felix, Intraaneurysmal flow: evaluation with Doppler guidewires, Am. J. Neuroradiol. 17 (1996) 1333-1337.

[4] C. Privat, A. Ravel, P. Chirossel, O. Borson, N. Perez, P. Bourlet, L. Walker, J.F. Viallet, L. Boyer, Endovascular Doppler guide wire in renal arteries: correlation with angiography in 20 patients, Invest. Radiol. 34 (1999) 530-535, https://doi.org/10.1097/00004424-199908000-00006

[5] T. Yamagami, O. Tanaka, R. Yoshimatsu, H. Miura, T. Suzuki, T. Hirota, T. Nishimura, Hepatic artery-targeting guidewire technique during transjugular 
intrahepatic portosystemic shunt, Br. J. Radiol. 84 (2011) 315-318, https://doi. org/10.1259/bjr/19972953

[6] B. Hsu, PET tracers and techniques for measuring myocardial blood flow in patients with coronary artery disease, J. Biomed. Res. 27 (2013) 452-459, https://doi.org/10.7555/JBR.27.20130136

[7] C. Andersson, J. Kihlberg, T. Ebbers, L. Lindström, C.J. Carlhäll, J.E. Engvall, Phase-contrast MRI volume flow - a comparison of breath held and navigator based acquisitions, BMC Med. Imaging 16 (2016) 26, https://doi.org/10.1186/ s12880-016-0128-X

[8] K. Johnson, P. Sharma, J. Oshinski, Coronary artery flow measurement using navigator echo gated phase contrast magnetic resonance velocity mapping at 3.0 T, J. Biomech. 41 (2008) 595-602, https://doi.org/10.1016/j.jbiomech.2007. 10.010

[9] P.D. Gatehouse, J. Keegan, L.A. Crowe, S. Masood, R.H. Mohiaddin, K.F. Kreitner, D.N. Firmin, Applications of phase-contrast flow and velocity imaging in cardiovascular MRI, Eur. Radiol. 15 (2005) 2172-2184, https://doi.org/10.1007/ s00330-005-2829-3

[10] D. Evans, W. McDicken, Doppler ultrasound: physics,instrumentation and signal processing, John Wiley \& Sons, 2000.

[11] J.W. Doucette, P. Douglas Corl, H.M. Payne, A.E. Flynn, M. Goto, M. Nassi, J. Segal, Validation of a Doppler guide wire for intravascular measurement of coronary artery flow velocity, Circulation. 85 (1992) 1899-1911.

[12] B. De Bruyne, N.H.J. Pijls, B. Kalesan, E. Barbato, P.A.L. Tonino, Z. Piroth, N. Jagic, S. Möbius-Winkler, G. Rioufol, N. Witt, P. Kala, P. MacCarthy, T. Engström, K.G. Oldroyd, K. Mavromatis, G. Manoharan, P. Verlee, O. Frobert, N. Curzen, J.B. Johnson, P. Jüni, W.F. Fearon, Fractional flow reserve-guided PCI versus medical therapy in stable coronary disease, N. Engl. J. Med. 367 (2012) 991-1001, https://doi.org/10.1056/NEJMoa1205361

[13] P.A.L. Tonino, B. De Bruyne, N.H.J. Pijls, U. Siebert, F. Ikeno, M. vant Veer, V. Klauss, G. Manoharan, T. Engstrøm, K.G. Oldroyd, P.N. Ver Lee, P.A. MacCarthy, W.F. Fearon, Fractional flow reserve versus angiography for guiding percutaneous coronary intervention, N. Engl. J. Med. 360 (2009) 213-224, https://doi.org/10.1056/NEJMoa0807611

[14] N.H.J. Pijls, J.A.M. Van Son, R.L. Kirkeeide, B. De Bruyne, K.L. Gould, Experimental basis of determining maximum coronary, myocardial, and collateral blood flow by pressure measurements for assessing functional stenosis severity before and after percutaneous transluminal coronary angioplasty, Circulation 87 (1993) 1354-1367, https://doi.org/10.1161/01.cir.87.4.1354

[15] B. De Bruyne, J. Sarma, Fractional flow reserve: a review, Heart 94 (2008) 949-959, https://doi.org/10.1136/hrt.2007.122838

[16] A. Jeremias, A.J. Kirtane, G.W. Stone, A test in context: fractional flow reserve: accuracy, prognostic implications, and limitations, J. Am. College Cardiol. 69 (2017) 2748-2758, https://doi.org/10.1016/j.jacc.2017.04.019

[17] T.P. van de Hoef, M. Siebes, J.A.E. Spaan, J.J. Piek, Fundamentals in clinical coronary physiology: why coronary flow is more important than coronary pressure, Eur. Heart J. 36 (2015) 3312-3319, https://doi.org/10.1093/eurheartj/ ehv235

[18] D. Garcia, B. Harbaoui, T.P. van de Hoef, M. Meuwissen, S.S. Nijjer, M. Echavarria-Pinto, J.E. Davies, J.J. Piek, P. Lantelme, Relationship between FFR, CFR and coronary microvascular resistance - practical implications for FFRguided percutaneous coronary intervention, PLoS One 14 (2019) e0208612, https://doi.org/10.1371/journal.pone.0208612

[19] B. De Bruyne, N.H.J. Pijls, L. Smith, M. Wievegg, G.R. Heyndrickx, Coronary thermodilution to assess flow reserve experimental validation, Circulation 104 (2001) 2003-2006, https://doi.org/10.1161/hc4201.099223

[20] N.H.J. Pijls, B. De Bruyne, L. Smith, W. Aarnoudse, E. Barbato, J. Bartunek, G.J.W. Bech, F. Van De Vosse, Coronary thermodilution to assess flow reserve: validation in humans, Circulation 105 (2002) 2482-2486, https://doi.org/10. 1161/01.CIR.0000017199.09457.3D

[21] W.F. Fearon, L.B. Balsam, H.M.O. Farouque, R.C. Robbins, P.J. Fitzgerald, P.G. Yock, A.C. Yeung, Novel index for invasively assessing the coronary microcirculation, Circulation 107 (2003) 3129-3132, https://doi.org/10.1161/01.CIR.0000080700. 98607.D1

[22] G.J. Martínez, A.S.C. Yong, W.F. Fearon, M.K.C. Ng, The index of microcirculatory resistance in the physiologic assessment of the coronary microcirculation, Coron. Artery Dis. 26 (2015) e15-e26, https://doi.org/10.1097/MCA. 0000000000000213

[23] H. Rahman, D. Corcoran, M. Aetesam-Ur-Rahman, S.P. Hoole, C. Berry, D. Perera, Diagnosis of patients with angina and non-obstructive coronary disease in the catheter laboratory, Heart 105 (2019) 1536-1542, https://doi.org/10.1136/ heartjnl-2019-315042

[24] S.J. Denardo, L. Talbot, V.K. Hargrave, A.R. Selfridge, T.A. Ports, P.G. Yock, Accuracy of Doppler catheter measurements: Effect of inhomogeneous beam power distribution on mean and peak velocity, J. Am. College Cardiol. 29 (1997) 283-292, https://doi.org/10.1016/S0735-1097(96)00482-2

[25] D. Sharif, A. Sharif-Rasslan, C. Shahla, A. Khalil, U. Rosenschein, Differences in coronary artery blood velocities in the setting of normal coronary angiography and normal stress echocardiography, Heart Int. 10 (2015) e6-e11, https://doi. org/10.5301/heartint.5000221

[26] H. Wieneke, C. Von Birgelen, M. Haude, H. Eggebrecht, S. Möhlenkamp, A. Schmermund, D. Böse, C. Altmann, T. Bartel, R. Erbel, Determinants of coronary blood flow in humans: quantification by intracoronary Doppler and ultrasound, J. Appl. Physiol. 98 (2005) 1076-1082, https://doi.org/10.1152/ japplphysiol.00724.2004

[27] A.S. Roy, R.K. Banerjee, L.H. Back, M.R. Back, S. Khoury, R.W. Millard, Delineating the guide-wire flow obstruction effect in assessment of fractional flow reserve and coronary flow reserve measurements, Am. J. Physiol. Circ. Physiol. 289 (2005) H392-H397, https://doi.org/10.1152/ajpheart.00798.2004

[28] L. Genuardi, Y.S. Chatzizisis, C. Chiastra, G. Sgueglia, H. Samady, G.S. Kassab, F. Migliavacca, C. Trani, F. Burzotta, Local fluid dynamics in patients with bifurcated coronary lesions undergoing percutaneous coronary interventions, Cardiol. J. 28 (2021) 321-329, https://doi.org/10.5603/CJ.a2020.0024

[29] G. Van Soest, E. Regar, A.F.W. Van Der Steen, Photonics in cardiovascular medicine, Nat. Photon. 9 (2015) 626-629, https://doi.org/10.1038/nphoton. 2015.177

[30] V. Mishra, N. Singh, U. Tiwari, P. Kapur, Fiber grating sensors in medicine: current and emerging applications, Sens. Actuators A Phys. 167 (2011) 279-290, https://doi.org/10.1016/j.sna.2011.02.045

[31] S. Pevec, D. Donlagić, Multiparameter fiber-optic sensors: a review, Opt. Eng. 58 (2019) 1-9, https://doi.org/10.1117/1.oe.58.7.072009

[32] A.G. Leal-Junior, C.A.R. Diaz, L.M. Avellar, M.J. Pontes, C. Marques, A. Frizera, Polymer optical fiber sensors in healthcare applications: a comprehensive review, Sensors 19 (2019) 3156, https://doi.org/10.3390/s19143156

[33] R. Correia, S. James, S.-W. Lee, S.P. Morgan, S. Korposh, Biomedical application of optical fibre sensors, J. Opt. 76 (2018) 073003-073074.

[34] J.M. Coote, E.J. Alles, S. Noimark, C.A. Mosse, C.D. Little, C.D. Loder, A.L. David R.D. Rakhit, M.C. Finlay, A.E. Desjardins, Dynamic physiological temperature and pressure sensing with phase-resolved low-coherence interferometry, Opt Express 27 (2019) 5641-5654, https://doi.org/10.1364/oe.27.005641

[35] I.J. Fox, History and developmental aspects of the indicator-dilution technique, Circ. Res. 10 (1962) 381-392, https://doi.org/10.1161/01.RES.10.3.381

[36] W. Ganz, R. Donoso, H.S. Marcus, J.S. Forrester, H.J.C. Swan, A new technique for measurement of cardiac output by thermodilution in man, Am. J. Cardiol. 27 (1971) 392-396, https://doi.org/10.1016/0002-9149(71)90436-X

[37] W. Ganz, K. Tamura, H.S. Marcus, R. Donoso, S. Yoshida, H.J.C. Swan, Measurement of coronary sinus blood flow by continuous thermodilution in man, Circulation 44 (1971) 181-195 〈http://circ.ahajournals.org/content/ circulationaha/44/2/181.full.pdf $\rangle$ accessed April 23, 2018.

[38] P. Meier, K.L. Zierler, On the theory of the indicator-dilution method for measurement of blood flow and volume, J. Appl. Physiol. 6 (1954) 731-744, https:// doi.org/10.1152/jappl.1954.6.12.731

[39] W. Ganz, H.J.C. Swan, Measurement of blood flow by thermodilution, Am. J. Cardiol. 29 (1972) 241-246, https://doi.org/10.1016/0002-9149(72)90635-2

[40] A. Gutiérrez-Barrios, E. Izaga-Torralba, F. Rivero Crespo, L. Gheorghe, D. Cañadas-Pruaño, J. Gómez-Lara, E. Silva, I. Noval-Morillas, R. Zayas Rueda, G. Calle-Pérez, R. Vázquez-García, F. Alfonso, Continuous thermodilution method to assess coronary flow reserve, Am. J. Cardiol. 141 (2021) 31-37, https://doi.org/10.1016/j.amjcard.2020.11.011

[41] K.L. Zierler, Circulation times and the theory of indicator dilution methods for determining blood flow and volumes, Handb. Physiol. (1962) 585-615.

[42] N.H. Pijls, G.J. Uijen, A. Hoevelaken, T. Arts, W.R. Aengevaeren, H.S. Bos, J.H. Fast, K.L. van Leeuwen, T. van der Werf, Mean transit time for the assessment of myocardial perfusion by videodensitometry, Circulation 81 (1990) 1331-1340, https://doi.org/10.1161/01.CIR.81.4.1331

[43] M. Özbek, H.F. Özel, N. Ekerbiçer, T. Zeren, A physical model of the thermodilution method: Influences of the variations of experimental setup on the accuracy of flow rate estimation, Biomed. Tech. 56 (2011) 59-64, https://doi. org/10.1515/BMT.2010.058

[44] A.C.A.P. Vliers, K.R. Visser, W.G. Zijlstra, Analysis of indicator distribution in the determination of cardiac output by thermal dilution, Cardiovasc. Res. 7 (1973) 125-132, https://doi.org/10.1093/cvr/7.1.125

[45] M. van't Veer, M.C.F. Geven, M.C.M. Rutten, A. van der Horst, W.H. Aarnoudse, N.H.J. Pijls, F.N. van de Vosse, Continuous infusion thermodilution for assessment of coronary flow: theoretical background and in vitro validation, Med Eng. Phys. 31 (2009) 688-694, https://doi.org/10.1016/j.medengphy.2009.01. 006

[46] X. Monnet, R. Persichini, M. Ktari, M. Jozwiak, C. Richard, J.L. Teboul, Precision of the transpulmonary thermodilution measurements, Crit. Care 15 (2011) 1-6 https://doi.org/10.1186/cc10421

[47] T. Nishikawa, S. Dohi, Errors in the measurement of cardiac output by thermodilution, Can. J. Anaesth. 40 (1993) 142-153.

[48] E. Carr, E.C. Mackle, M.C. Finlay, C.A. Mosse, J.M. Coote, I. Papakonstantinou, A.E. Desjardins, Optical interferometric temperature sensors for intravascular blood flow measurements, Proc. SPIE, Novel Biophotonics Techniques and Applications V, (22 July 2019) 11075 (2019) 1107502, https://doi.org/10.1117/12. 2527056

[49] J.S. Lundsgaard, J. Gronlund, N. Einer-Jensen, Evaluation of a constant-temperature hot-wire anemometer for respiratory-gas-flow measurements, Med. Biol. Eng. Comput. 17 (1979) 211-215.

[50] L.M. Fingerson, Thermal anemometry, current state, and future directions, Rev. Sci. Instrum. 65 (1994) 285-300, https://doi.org/10.1063/1.1145187

[51] H.H. Bruun, Hot-wire anemometry: principles and signal analysis, Meas. Sci. Technol. 7 (1996), https://doi.org/10.1088/0957-0233/7/10/024

[52] R.G. Johnson, R.E. Higashi, A highly sensitive silicon chip microtransducer for air flow and differential pressure sensing applications, Sens. Actuators 11 (1987) 63-72, https://doi.org/10.1016/0250-6874(87)85005-9

[53] M. Ashauer, H. Glosch, F. Hedrich, N. Hey, H. Sandmaier, W. Lang, Thermal flow sensor for liquids and gases based on combinations of two principles, Sens. Actuators A Phys. 73 (1999) 7-13, https://doi.org/10.1016/S0924-4247(98) 00248-9

[54] S. Gao, A.P. Zhang, H. Tam, L.H. Cho, C. Lu, All-optical fiber anemometer based on laser heated fiber Bragg gratings, Opt. Express 19 (2011) 10124-10130. 
[55] X. Dong, Y. Zhou, W. Zhou, J. Cheng, Z. Su, Compact anemometer using silvercoated fiber Bragg Grating, IEEE Photon. J. 4 (2012) 1381-1386, https://doi.org/ 10.1109/JPHOT.2012.2208946

[56] Z. Liu, L. Htein, L.-K. Cheng, Q. Martina, R. Jansen, H.-Y. Tam, Highly sensitive miniature fluidic flowmeter based on an FBG heated by Co2+-doped fiber, Opt. Express 25 (2017) 4393-4402, https://doi.org/10.1364/0E.25.004393

[57] L.J. Cashdollar, K.P. Chen, Fiber Bragg grating flow sensors powered by in-fiber light, IEEE Sens. J. 5 (2005) 1327-1331, https://doi.org/10.1109/JSEN.2005. 855599

[58] G. Comte-Bellot, Hot-wire anemometry, Annu. Rev. Fluid Mech. 8 (1976) 209-231, https://doi.org/10.1146/annurev.fl.08.010176.001233

[59] A.S. Morris, R. Langari, Measurement and Instrumentation: Theory and Application, (2012) Academic Press 〈https://books.google.co.uk/books?hl=en\& $\mathrm{lr}=\& \mathrm{id}=\mathrm{arw} 7 \mathrm{FIVkVb} 4 \mathrm{C} \& \mathrm{oi}=\mathrm{fnd} \& \mathrm{pg}=\mathrm{PP} 2 \& \mathrm{dq}=$ morris+and+langari\&ots= 3D04T0jFN6\&sig=5B0ovezWwvgImKC3-IY4RB-crCY\#v=onepage \&q=morris and langari\&f=false $>$ accessed June 18, 2019.

[60] A. Van der Horst, M.C.F. Geven, M.C.M. Rutten, N.H.J. Pijls, F.N. van de Vosse, Thermal anemometric assessment of coronary flow reserve with a pressuresensing guide wire: an in vitro evaluation, Med. Eng. Phys. 33 (2011) 684-691, https://doi.org/10.1016/j.medengphy.2011.01.004

[61] A. Van der Horst, M. Van't Veer, R.A.M. Van der Sligte, M.C.M. Rutten, N.H.J. Pijls, F.N. Van de Vosse, A combination of thermal methods to assess coronary pressure and flow dynamics with a pressure-sensing guide wire, Med. Eng. Phys. 35 (2013) 298-309, https://doi.org/10.1016/j.medengphy.2012.05.002

[62] A. Ruiz-Vargas, S.A. Morris, R.H. Hartley, J.W. Arkwright, Optical flow sensor for continuous invasive measurement of blood flow velocity, J. Biophoton. 12 (2019) 201900139, https://doi.org/10.1002/jbio.201900139

[63] D.J. Webb, Optical-fiber sensors: an overview, MRS Bull. 27 (2002) 365-369.

[64] W. Talataisong, R. Ismaeel, G. Brambilla, A review of microfiber-based temperature sensors, Sensors 18 (2018) 461, https://doi.org/10.3390/s18020461

[65] E. Schena, D. Tosi, P. Saccomandi, E. Lewis, T. Kim, Fiber optic sensors for temperature monitoring during thermal treatments: an overview, Sensors 16 (2016) 1144, https://doi.org/10.3390/s16071144

[66] P. Roriz, S. Silva, O. Frazão, S. Novais, Optical fiber temperature sensors and their biomedical applications, Sensors (Switz) 20 (2020), https://doi.org/10. 3390/s20072113

[67] J. Cheng, W. Zhu, Z. Huang, P. Hu, Experimental and simulation study on thermal gas flowmeter based on fiber Bragg grating coated with silver film, Sens. Actuators A Phys. 228 (2015) 23-27, https://doi.org/10.1016/j.sna.2015.02.033

[68] X. Wang, X. Dong, Y. Zhou, N. Kai, J. Cheng, Z. Chen, Fiber optic anemometer based on metal-coated fibre Bragg grating, Inf. Commun. Signal Process (2013) $10-11$.

[69] J. Cheng, Y. Zhou, X. Dong, W. Zhou, Fiber-optic thermal anemometer based on metallic coated fiber Bragg, Fiber-optic Thermal Anemometer Based on Metallic Coated fiber Bragg, Proc. SPIE, 2012, https://doi.org/10.1117/12.970514

[70] X. Wang, X. Dong, Y. Zhou, Y. Li, J. Cheng, Z. Chen, Optical fiber anemometer using silver-coated fiber Bragg grating and bitaper, Sens. Actuators A Phys. 214 (2014) 230-233, https://doi.org/10.1016/j.sna.2014.04.013

[71] X. Wang, X. Dong, Y. Zhou, K. Ni, J. Cheng, Z. Chen, Hot-wire anemometer based on silver-coated fiber Bragg grating assisted by no-core fiber, IEEE Photon. Technol. Lett. 25 (2013) 11-15, https://doi.org/10.1109/LPT.2013.2288634

[72] I. Bennion, J.A.R. Williams, L. Zhang, K. Sudgen, N. Doran, UV-written in-fibre Bragg gratings, Opt. Quantum Electron. 28 (1996) 93-135.

[73] A. Othonos, K. Kalli, D. Pureur, A. Mugnier, Fibre Bragg gratings, Wavel. Filters Fibre Opt. Springer Berlin Heidelberg, 2006, pp. 189-269.

[74] J.T.W. Kuo, L. Yu, E. Meng, Micromachined thermal flow sensors - a review, Micromachines 3 (2012) 550-573, https://doi.org/10.3390/mi3030550

[75] M.G. Xu, J.L. Archambault, L. Reekie, J. Dakin, Thermally-compensated bending gauge using surface-mounted fibre gratings, Int. J. Optoelectron. 9 (1994) 281-283 〈https://eprints.soton.ac.uk/78268/〉 accessed June 21, 2019.

[76] M. Song, B. Lee, S.B. Lee, S.S. Choi, Interferometric temperature-insensitive strain measurement with different-diameter fiber Bragg gratings, Opt. Lett. 22 (1997) 790-792, https://doi.org/10.1364/ol.22.000790

[77] M. Song, S.B. Lee, S.S. Choi, B. Lee, Simultaneous measurement of temperature and strain using two fiber Bragg gratings embedded in a glass tube, Opt. Fiber Technol. 3 (1997) 194-196, https://doi.org/10.1006/ofte.1997.0215

[78] S.W. James, M.L. Dockney, R.P. Tatam, Simultaneous independent temperature and strain measurement using in-f ibre Bragg grating sensors, Electron. Lett. 32 (1996) 1133-1134, https://doi.org/10.1049/el:19960732

[79] G. Rajan, M. Ramakrishnan, Y. Semenova, K. Milenko, P. Lesiak, A.W. Domanski, T.R. Wolinski, G. Farrell, A photonic crystal fiber and fiber Bragg grating-based hybrid fiber-optic sensor system, IEEE Sens. J. 12 (2012) 39-43, https://doi.org/ 10.1109/JSEN.2011.2114650

[80] Y. Zhao, P. Wang, R. Lv, X. Liu, Highly sensitive airflow sensor based on Fabry-Perot interferometer and vernier effect, J. Light. Technol. 34 (2016) 5351-5356, https://doi.org/10.1109/JLT.2016.2615054

[81] C.-L. Lee, W.-Y. Hong, H.-J. Hsieh, Z.-Y. Weng, Air gap fiber Fabry-Pérot interferometer for highly sensitive micro-airflow sensing, IEEE Photon. Technol. Lett. 23 (2011) 905-907, https://doi.org/10.1109/LPT.2011.2142413

[82] G. Liu, Q. Sheng, W. Hou, M. Han, Optical fiber vector flow sensor based on a silicon Fabry - Perot interferometer array, Opt. Lett. 41 (2016) 3-6.

[83] Y. Li, G. Yan, L. Zhang, S. He, Microfluidic flowmeter based on micro “ hot- wire" sandwiched Fabry-Perot interferometer, Opt. Express 23 (2015) 9483-9493, https://doi.org/10.1364/OE.23.009483
[84] B. Zhou, H. Jiang, C. Lu, S. He, Hot cavity optical fiber Fabry - Perot interferometer as a flow sensor with temperature self-calibrated, J. Light. Technol. 34 (2016) 5044-5048.

[85] L.C. Bobb, J.P. Davis, A. Samouris, D.C. Larson, An optical fiber hot-wire anemometer, Fiber Opt. Laser Sensors VII, SPIE, 1990, p. 567, https://doi.org/10.1117 12.963076

[86] Y. Zhao, H.F. Hu, D.J. Bi, Y. Yang, Research on the optical fiber gas flowmeters based on intermodal interference, Opt. Lasers Eng. 82 (2016) 122-126, https:/ doi.org/10.1016/j.optlaseng.2016.02.012

[87] Y. Zhang, F. Wang, Z. Duan, Z. Liu, Z. Liu, Z. Wu, Y. Gu, A novel low-powerconsumption all-fiber-optic anemometer with simple system design, Sensors 17 (2017), https://doi.org/10.3390/s17092107

[88] Y. Liu, B. Liang, X. Zhang, N. Hu, K. Li, F. Chiavaioli, X. Gui, T. Guo, Plasmonic fiber-optic photothermal anemometers with carbon nanotube coatings, J. Light. Technol. 37 (2019) 3373-3380, https://doi.org/10.1109/JLT.2019.2916572

[89] G. Liu, W. Hou, W. Qiao, M. Han, Fast-response fiber-optic anemometer with temperature self-compensation, Opt. Express 23 (2015) 13562-13570, https:/ doi.org/10.1364/OE.23.013562

[90] T.O.H. Charrett, S.W. James, R.P. Tatam, Optical fibre laser velocimetry: a review, Meas. Sci. Technol. 23 (2012) 1-32, https://doi.org/10.1088/0957-0233/23/3/ 032001

[91] C.M. Penney, Differential doppler velocity measurements, Appl. Phys. Lett. 16 (1970) 167-169, https://doi.org/10.1063/1.1653147

[92] L. Scalise, W. Steenbergen, F. de Mul, Self-mixing feedback in a laser diode for intra-arterial optical blood velocimetry, Appl. Opt. 40 (2001) 4608-4615, https://doi.org/10.1364/ao.40.004608

[93] F.F.M. De Mul, L. Scalise, A.L. Petoukhova, M. Van Herwijnen, P. Moes, W. Steenbergen, Glass-fiber self-mixing intra-arterial laser Doppler velocimetry: signal stability and feedback analysis, Appl. Opt. 41 (2002) 658-667. https://doi.org/10.1364/A0.41.000658

[94] M.H. Koelink, F.F.M. de Mul, A.L. Weijers, J. Greve, R. Graaff, A.C.M. Dassel J.G. Aarnoudse, Fiber-coupled self-mixing diode-laser Doppler velocimeter: technical aspects and flow velocity profile disturbances in water and blood flows, Appl. Opt. 33 (1994) 5628-5641, https://doi.org/10.1364/ao.33.005628

[95] H. Nishihara, J. Koyama, N. Hoki, F. Kajiya, M. Hironaga, M. Kano, Optical-fiber laser Doppler velocimeter for high-resolution measurement of pulsatile blood flows, Appl. Opt. 21 (1982) 1785-1790, https://doi.org/10.1364/A0.21.001785

[96] K. Meigas, H. Hinrikus, R. Kattai, J. Lass, Self-mixing in a diode laser as a method for cardiovascular diagnostics, J. Biomed. Opt. 8 (2003) 152-160, https://doi. org/10.1117/1.1528949

[97] T. Tanaka, C. Riva, I. Ben-Sira, Blood velocity measurements in human retinal vessels, Science 186 (1974) 830-831.

[98] E. Göran Salerud, P.Åke Öberg, Single-fibre laser Doppler flowmetry, Med. Biol. Eng. Comput. 25 (1987) 329-334, https://doi.org/10.1007/BF02447433

[99] H. Cai, S.-E. Larsson, P.A. Oberg, Single fiber Laser-Doppler flowmetry-dependence on wavelength and tip optics, J. Biomed. Opt. 3 (1998) 334-339, https://doi.org/10.1117/1.429892

[100] M.D. Stern, D.L. Lappe, P.D. Bowen, J.E. Chimosky, G.A. Holloway, H.R. Keiser R.L. Bowman, Continuous measurement of tissue blood flow by laser-Doppler spectroscopy, Am. J. Physiol. 232 (1977) H441-H448 〈http://ajpheart. physiology.org/ $\rangle$.

[101] T. Tanaka, G.B. Benedek, Measurement of the velocity of blood flow (in vivo) using a fiber optic catheter and optical mixing spectroscopy, Appl. Opt. 14 (1975) 189-196, https://doi.org/10.1364/ao.14.000189

[102] S.N. Khotiaintsev, V. Svirid, L. Glebova, Laser Doppler velocimeter miniature differential probe for biomedical applications, Biomed. Syst. Technol. International Society for Optics and Photonics, 1996, pp. 158-164, https://doi. $\operatorname{org} / 10.1117 / 12.259953$

[103] Y. Li, S. Meersman, R. Baets, Optical frequency shifter on SOI using thermo-optic serrodyne modulation, in: IEEE Int. Conf. Gr. IV Photonics GFP, 2010: pp. 75-77. doi:10.1109/GROUP4.2010.5643423.

[104] H. Ishida, T. Andoh, S. Akiguchi, H. Shirakawa, D. Kobayashi, Y. Kuraishi, T. Hachiga, Blood flow velocity imaging of malignant melanoma by micro multipoint laser Doppler velocimetry, Appl. Phys. Lett. 97 (2010) 103702-103742, https://doi.org/10.1063/1.3486678

[105] G. Tomonaga, H. Mitake, N. Hoki, F. Kajiya, Measurement of point velocity in the canine coronary artery by laser Doppler velocimeter with optical fiber, Jpn. J. Surg. 11 (1981) 226-231, https://doi.org/10.1007/BF02468760

[106] F. Kajiya, N. Hoki, G. Tomonaga, H. Nishihara, A Laser-Doppler-velocimeter using an optical fiber and its application to local velocity measurement in the coronary artery, Experientia 37 (1981) 1171-1173, https://doi.org/10.1007/ BF01989901

[107] F. Kajiya, K. Tsujioka, M. Goto, Y. Wada, S. Tadaoka, M. Nakai, O. Hiramatsu, Y. Ogasawara, K. Mito, N. Hoki, G. Tomonaga, Evaluation of phasic blood flow velocity in the great cardiac vein by a laser Doppler method, Heart Vessels 1 (1985) 16-23, https://doi.org/10.1007/BF02066482

[108] T. Tajikawa, W. Ishihara, S. Kohri, K. Ohba, Development of miniaturized fiberoptic laser Doppler velocimetry sensor for measuring local vlood velocity: measurement of whole blood velocity in model blood vessel using a fiber-optic sensor with a convex lens-Like tip, J. Sens. 2012 (2012) 1-11, https://doi.org/10. 1155/2012/426476

[109] F. Kajiya, Progress and recent topics in blood flow measurements., Front. Med. Biol. Eng. 1 (1989) 271-285. 〈https://europepmc.org/article/med/2486915 (accessed May 21, 2021). 
[110] D. Kilpatrick, J.V. Tyberg, W.W. Parmley, Blood velocity measurement by fiber optic laser Doppler anemometry, IEEE Trans. Biomed. Eng. BME- 29 (1982) 142-145, https://doi.org/10.1109/TBME.1982.325021

111] F. Kajiya, K. Mito, Y. Ogasawara, K. Tsujioka, G. Tomonaga, H. Nishihara, M. Hironaga, M. Kano, Laser Doppler Blood Flow Velocimeter With An Optical Fiber And Its Application To Detailed Measurements Of The Coronary Blood Flow Velocities, Nov. Opt. Fiber Tech. Med. Appl. International Society for Optics and Photonics, 1984, p. 25, https://doi.org/10.1117/12.943903

[112] O. Sezerman, B.E. Paton, G.A. Klassen, J.A. Armour, Fibre optic laser Doppler velocimeter for medical applications, Fibre Optic Laser Doppler Velocimeter For Medical Applications, Proc. SPIE, International Society for Optics and Photonics, 1986, p. 93, https://doi.org/10.1117/12.950735

[113] D. Kilpatrick, T. Linderer, R.E. Sievers, J.V. Tyberg, Measurement of coronary sinus blood flow by fiber-optic laser Doppler anemometry, Am. J. Physiol. Heart Circ. Physiol. 11 (1982) 1111-1114, https://doi.org/10.1152/ajpheart.1982. 242.6.h1111

[114] M.D. Stern, Catheter Velocimeters, Laser-Doppler Blood Flowmetry, Springer, Boston, MA 1990, pp. 109-120, https://doi.org/10.1007/978-1-4757-2083-9 7

[115] F. Kajiya, Characteristics and possible origins of blood velocity waveforms of the epicardial and intramyocardial coronary circulation in the ventricles and the Atria, Coron. Circ. Physiol. Pathophysiol. States, Springer, Japan, 1991, pp. 1-19, https://doi.org/10.1007/978-4-431-68108-3_1

[116] F. Kajiya, O. Hiramatsu, Y. Ogasawara, K. Mito, K. Tsujioka, Dual-fiber laser doppler velocimeter and its application to the measurements of coronary blood velocity, Biorheology 25 (1988) 227-235, https://doi.org/10.3233/BIR-1988251-231

[117] F. Kajiya, G. Tomonaga, K. Tsujioka, Y. Ogasawara, H. Nishihara, Evaluation of local blood flow velocity in proximal and distal coronary arteries by laser Doppler method, J. Biomech. Eng. 107 (1985) 10-15, https://doi.org/10.1115/1. 3138511

[118] F. Kajiya, O. Hiramatsu, K. Mito, Y. Ogasawara, K. Tsujioka, An optical-fiber laser Doppler velocimeter and its application to measurements of coronary blood flow velocities, Med. Prog. Technol. 12 (1987) 77-85, https://doi.org/10.1007/ 978-94-009-3361-3_8

1119] F. Kajiya, O. Hiramatsu, K. Mito, S. Tadaoka, Y. Ogasawara, K. Tsujioka, Evaluation of coronary blood flow by fiber-optic laser Doppler velocimeter, Coron. Circ. Springer, Japan, 1990, pp. 43-53, https://doi.org/10.1007/978-4-431-68087-1_3

[120] K. Mito, Y. Ogasawara, O. Hiramatsu, K. Tsujioka, F. Kajiya, A laser Doppler catheter for monitoring both phasic and mean coronary vein flow, Heart Vessels 6 (1990) 1-8, https://doi.org/10.1007/BF02301875

[121] T. Tajikawa, M. Takeshige, W. Ishihara, S. Kohri, K. Ohba, Development of miniaturized fiber-optic laser Doppler velocimetry sensor for measurement of local blood velocity, J. Fluid Sci. Technol. 4 (2009) 62-74, https://doi.org/10. $1299 /$ jfst.4.62

[122] S. Kohri, T. Tajikawa, K. Ohba, Development of a miniaturized fiber-optic LDV sensor for local blood velocity measurement, Biomed. Eng. Res. 2 (2013) 131-138, https://doi.org/10.5963/BER0203002

[123] K. Ohba, N. Fujiwara, Development of fiber optic laser Doppler velocimeter for measurement of local blood velocity, in: Proc. SPIE, International Society for Optics and Photonics, 1993: pp. 195-201. doi:10.1117/12.150504.

[124] V.I. Krasovskii, I.N. Feofanov, P.I. Ivashkin, M.A. Kazaryan, A fiber-optic Doppler blood flow-velocity sensor, St. Petersbg, Polytech. Univ. J. Phys. Math. 3 (2017) 35-38, https://doi.org/10.1016/J.SPJPM.2017.03.006

[125] J. Knuhtsen, E. Olldag, P. Buchhave, Fibre-optic laser Doppler anemometer with Bragg frequency shift utilising polarisation-preserving single-mode fibre, J. Phys. E. 15 (1982) 1188-1191, https://doi.org/10.1088/0022-3735/15/11/015

[126] P. Le-Cong, B.W. Zweifach, In vivo and in vitro velocity measurements in microvasculature with a laser, Microvasc. Res. 17 (1979) 131-141, https://doi.org/ 10.1016/0026-2862(79)90402-3

[127] L.N. Toksvang, R.M.G. Berg, Using a classic paper by Robin Fåhraeus and Torsten Lindqvist to teach basic hemorheology, Adv. Physiol. Educ. 37 (2013) 129-133, https://doi.org/10.1152/advan.00009.2013

[128] B.E. Bouma, M. Villiger, K. Otsuka, W.-Y, Oh, Intravascular optical coherence tomography [Invited], Biomed. Opt. Express 8 (2017) 2660-2686, https://doi. org/10.1364/boe.8.002660

[129] B.J. Vakoc, S.H. Yun, J.F. de Boer, G.J. Tearney, B.E. Bouma, Phase-resolved optical frequency domain imaging, Opt. Express 13 (2005) 5483-5493, https://doi.org/ 10.1364/opex.13.005483

[130] C. Sun, F. Nolte, K.H.Y. Cheng, B. Vuong, K.K.C. Lee, B.A. Standish, B. Courtney, T.R. Marotta, A. Mariampillai, V.X.D. Yang, In vivo feasibility of endovascular Doppler optical coherence tomography, Biomed. Opt. Express 3 (2012) 2600-2610, https://doi.org/10.1364/boe.3.002600

[131] B. Vuong, A.M.D. Lee, T.W.H. Luk, C. Sun, S. Lam, P. Lane, V.X.D. Yang, High speed, wide velocity dynamic range Doppler optical coherence tomography (Part IV): split spectrum processing in rotary catheter probes, Opt. Express 22 (2014) 7399-7415, https://doi.org/10.1364/oe.22.007399

[132] B. Vuong, H. Genis, R. Wong, J. Ramjist, J. Jivraj, H. Farooq, C. Sun, V.X.D. Yang, Evaluation of hemodynamics changes during interventional stent placement using Doppler optical coherence tomography, in: H. Hirschberg, S.J. Madsen, E.D. Jansen, Q. Luo, S.K. Mohanty, N.V. Thakor (Eds.), Opt. Tech. Neurosurgery, Neurophotonics, Optogenetics II, SPIE, 2015, p. 93050Q, https://doi.org/10.1117/ 12.2080635

[133] B. Vuong, H. Genis, R. Wong, J. Ramjist, J. Jivraj, C. Sun, Visualization of blood flow in carotid artery stenting with endovascular Doppler optical coherence tomography imaging and computational fluid dynamic modeling, in: 10th Pacific Symp. Flow Vis. Image Process., 2015.
[134] D. Barrows, B. Vuong, K. Lee, J. Jivraj, V.X.D. Yang, Graphics processor unit acceleration enables realtime endovascular Doppler optical coherence tomography imaging, Opt. Coherence Tomogr. Coherence Domain Opt. Methods Biomed. XXI, SPIE, 2017, https://doi.org/10.1117/12.2254930

[135] T. Wang, T. Pfeiffer, J. Daemen, F. Mastik, W. Wieser, A.F.W. Van Der Steen, R. Huber, G. Van Soest, Simultaneous morphological and flow imaging enabled by megahertz intravascular Doppler optical coherence tomography, IEEE Trans. Med. Imaging 39 (2020) 1535-1544, https://doi.org/10.1109/TMI.2019.2948258

[136] B.J. Vakoc, S.H. Yun, J.F. de Boer, G.J. Tearney, B.E. Bouma, Phase-resolved optical frequency domain imaging, Opt. Express 13 (2005) 5483-5493, https://doi.org/ 10.1364/opex.13.005483

[137] T. Wang, T. Pfeiffer, J. Daemen, F. Mastik, W. Wieser, A.F.W. Van Der Steen R. Huber, G. Van Soest, Simultaneous morphological and flow imaging enabled by megahertz intravascular Doppler optical coherence tomography, IEEE Trans. Med. Imaging 39 (2020) 1535-1544, https://doi.org/10.1109/TMI.2019.2948258

[138] N. Uribe-Patarroyo, M. Villiger, B.E. Bouma, Quantitative technique for robust and noise-tolerant speed measurements based on speckle decorrelation in optical coherence tomography, Opt. Express 22 (2014) 24411-24429, https:// doi.org/10.1364/oe.22.024411

[139] N. Uribe-Patarroyo, A.L. Post, S. Ruiz-Lopera, D.J. Faber, B.E. Bouma, Noise and bias in optical coherence tomography intensity signal decorrelation, OSA Contin. 3 (2020) 709-741, https://doi.org/10.1364/osac.385431

[140] F.A. Lupotti, F. Mastik, S.G. Carlier, C.L. De Korte, W.J. Van Der Giessen P.W. Serruys, A.F.W. Van Der Steen, Quantitative IVUS blood flow: validation in vitro, in animals and in patients, Ultrasound Med. Biol. 29 (2003) 507-515, https://doi.org/10.1016/S0301-5629(02)00774-3

[141] W. Yu, T. Tanigaki, D. Ding, P. Wu, H. Du, L. Ling, B. Huang, G. Li, W. Yang S. Zhang, F. Yan, M. Okubo, B. Xu, H. Matsuo, W. Wijns, S. Tu, Accuracy of intravascular ultrasound-based fractional flow reserve in identifying hemodynamic significance of coronary stenosis, Circ. Cardiovasc. Interv. 14 (2021) 175-183, https://doi.org/10.1161/CIRCINTERVENTIONS.120.009840

[142] W. Yu, J. Huang, D. Jia, S. Chen, O.C. Raffel, D. Ding, F. Tian, J. Kan, S. Zhang F. Yan, Y. Chen, H.G. Bezerra, W. Wijns, S. Tu, Diagnostic accuracy of intracoronary optical coherence tomography-derived fractional flow reserve for assessment of coronary stenosis severity, EuroIntervention 15 (2019) 189-197, https://doi.org/10.4244/EIJ-D-19-00182

[143] J.L. Gutiérrez-Chico, Y. Chen, W. Yu, D. Ding, J. Huang, P. Huang, J. Jing, M. Chu, P. Wu, F. Tian, B. Xu, S. Tu, Diagnostic accuracy and reproducibility of optical flow ratio for functional evaluation of coronary stenosis in a prospective series, Cardiol. J. 27 (2020) 350-361, https://doi.org/10.5603/CJ.a2020.0071

[144] J. Huang, H. Emori, D. Ding, T. Kubo, W. Yu, P. Huang, S. Zhang, J.L. GutiérrezChico, T. Akasaka, W. Wijns, S. Tu, Diagnostic performance of intracoronary optical coherence tomography-based versus angiography-based fractional flow reserve for the evaluation of coronary lesions, EuroIntervention 16 (2020) 568-576, https://doi.org/10.4244/eij-d-19-01034

[145] H. Gupta, V. Arumuru, R. Jha, Industrial fluid flow measurement using optical fiber sensors: a review, IEEE Sens. J. 21 (2021) 7130-7144, https://doi.org/10. 1109/JSEN.2020.3045506

[146] R. Posey, G.A. Johnson, S.T. Vohra, Strain sensing based on coherent Rayleigh scattering in an optical fibre, Electron. Lett. 36 (2000) 1688-1689, https://doi. org/10.1049/el:20001200

[147] Y. Muanenda, C.J. Oton, F. Di Pasquale, Application of Raman and Brillouin scattering phenomena in distributed optical fiber sensing, Front. Phys. 7 (2019) 155, https://doi.org/10.3389/fphy.2019.00155

[148] T. Kurashima, T. Horiguchi, M.T.-O. Letters, U, Distributed-temperature sensing using stimulated Brillouin scattering in optical silica fibers, Opt. Lett. 15 (1990) (1990) 1038-1040.

[149] A. Barrias, J. Casas, S. Villalba, A review of distributed optical fiber sensors for civil engineering applications, Sensors 16 (2016) 748, https://doi.org/10.3390/ s16050748

[150] C.Y. Hong, Y.F. Zhang, G.W. Li, M.X. Zhang, Z.X. Liu, Recent progress of using Brillouin distributed fiber optic sensors for geotechnical health monitoring, Sens. Actuators A Phys. 258 (2017) 131-145, https://doi.org/10.1016/j.sna.2017. 03.017

[151] B. Glisic, D. Inaudi, Fibre Optic Methods for Structural Health Monitoring, John Wiley and Sons, 2008

[152] G. Yilmaz, S.E. Karlik, A distributed optical fiber sensor for temperature detection in power cables, Sens. Actuators A Phys. 125 (2006) 148-155, https:// doi.org/10.1016/J.SNA.2005.06.024

[153] C.A. Galindez-Jamioy, J.M. López-Higuera, Brillouin distributed fiber sensors: an overview and applications, J. Sens. 2012 (2012) 204121, https://doi.org/10.1155/ 2012/204121

[154] W. Zou, X. Long, J. Chen, Brillouin scattering in optical fibers and its application to distributed sensors, Adv. Opt. Fiber Technol. Fundam. Opt. Phenom. Appl. InTech, 2015, https://doi.org/10.5772/59145

[155] A.H. Reshak, M.M. Shahimin, S.A.Z. Murad, S. Azizan, Simulation of Brillouin and Rayleigh scattering in distributed fibre optic for temperature and strain sensing application, Sens. Actuators A Phys. 190 (2013) 191-196, https://doi.org/10. 1016/j.sna.2012.11.034

[156] Z. Yu, M. Zhang, H. Dai, L. Liu, J. Zhang, X. Jin, G. Wang, Distributed optical fiber sensing with Brillouin optical time domain reflectometry based on differentia pulse pair, Opt. Laser Technol. 105 (2018) 89-93, https://doi.org/10.1016/j. optlastec.2018.02.037

[157] T. Chen, Q. Wang, B. Zhang, R. Chen, K.P. Chen, H. Wang, C.P. Chen, C.M. Chang, C.P. Lin, C.H. Lin, L.M. Fu, C.Y. Lee, Distributed flow sensing using optical hot -wire grid, Opt. Express 20 (2012) 8240-8249 〈https://www.osapublishing.org 
DirectPDFAccess/997B16D7-A5A6-C1EB-6F04C766DD5ADCDB 231528/oe-208-8240.pdf?da=1\&id=231528\&seq=0\&mobile=no $\rangle$ accessed February 28, 2018.

[158] M.T.V. Wylie, A.W. Brown, B.G. Colpitts, Distributed hot-wire anemometry based on Brillouin optical time-domain analysis, Opt. Express 20 (2012) 381-386.

[159] A. Garcia-Ruiz, A. Dominguez-Lopez, J. Pastor-Graells, H.F. Martins, S. MartinLopez, M. Gonzalez-Herraez, Long-range distributed optical fiber hot-wire anemometer based on chirped-pulse ФOTDR, Opt. Express 26 (2018) 463-476, https://doi.org/10.1364/oe.26.000463

[160] L. Mescia, F. Prudenzano, Advances on optical fiber sensors, Fibers 2 (2013) 1-23, https://doi.org/10.3390/fib2010001

[161] P. Caldas, P.A.S. Jorge, G. Rego, O. Frazão, J.L. Santos, L.A. Ferreira, F. Araújo, Fiber optic hot-wire flowmeter based on a metallic coated hybrid long period grating/fiber Bragg grating structure, Appl. Opt. 50 (2011) 2738-2743.

[162] Y.J. Rao, Optical in-fiber Bragg grating sensor systems for medical applications, J. Biomed. Opt. 3 (1998) 38-44, https://doi.org/10.1117/1.429860

[163] D. Tosi, E.G. Macchi, M. Gallati, G. Braschi, A. Cigada, S. Rossi, G. Leen, E. Lewis, Fiber-optic chirped FBG for distributed thermal monitoring of ex-vivo radiofrequency ablation of liver, Biomed. Opt. Express 5 (2014) 1799-1811, https:// doi.org/10.1364/boe.5.001799

[164] M. Willsch, T. Bosselmann, P. Kraemmer, R. Gerner, Distributed optical flow sensing using a novel fiber Bragg grating sensor, Distributed Optical Flow Sensing Using a Novel Fiber Bragg Grating Sensor, International Society for Optics and Photonics, 2005, p. 286, https://doi.org/10.1117/12.624023

[165] S. Iskander-Rizk, A.F.W. van der Steen, G. van Soest, Photoacoustic imaging for guidance of interventions in cardiovascular medicine, Phys. Med. Biol. 64 (2019), https://doi.org/10.1088/1361-6560/ab1ede

[166] H. Fang, K. Maslov, L.V. Wang, Photoacoustic doppler effect from flowing small light-absorbing particles, Phys. Rev. Lett. 99 (2007) 184501, https://doi.org/10. 1103/PhysRevLett.99.184501

[167] P. Van Den Berg, K. Daoudi W.S.- Photoacoustics, undefined 2015, Review of photoacoustic flow imaging: its current state and its promises, Elsevier. (n.d.). 〈https://www.sciencedirect.com/science/article/pii/S2213597915000270〉 (accessed June 14, 2021).

[168] J. Yao, K.I. Maslov, Y. Shi, L.A. Taber, L.V. Wang, In vivo photoacoustic imaging of transverse blood flow by using Doppler broadening of bandwidth, Opt. Lett. 35 (2010) 1419-1421, https://doi.org/10.1364/ol.35.001419

[169] L. Wang, C. Zhang, L.V. Wang, Grueneisen relaxation photoacoustic microscopy, Phys. Rev. Lett. 113 (2014) 174301, https://doi.org/10.1103/PhysRevLett.113. 174301

[170] R. Pakdaman Zangabad, S. Iskander-Rizk, P. van der Meulen, B. Meijlink, K. Kooiman, T. Wang, A.F.W. van der Steen, G. van Soest, Photoacoustic flow velocity imaging based on complex field decorrelation, Photoacoustics 22 (2021) 100256, https://doi.org/10.1016/j.pacs.2021.100256

[171] M.C. Finlay, C.A. Mosse, R.J. Colchester, S. Noimark, E.Z. Zhang, S. Ourselin, P.C. Beard, R.J. Schillin, I.P. Parkin, I. Papakonstantinou, A.E. Desjardins, Throughneedle all-optical ultrasound imaging in vivo: a preclinical swine study, Light Sci. Appl. 6 (2017) e17103-e17107, https://doi.org/10.1038/lsa.2017.103

[172] R.J. Colchester, C. Little, G. Dwyer, S. Noimark, E.J. Alles, E.Z. Zhang, C.D. Loder, I.P. Parkin, I. Papakonstantinou, P.C. Beard, M.C. Finlay, R.D. Rakhit, A.E. Desjardins, All-optical rotational ultrasound imaging, Sci. Rep. 9 (2019) 1-8, https://doi.org/10.1038/s41598-019-41970-z

[173] B.E.P.M. Claessen, M. Bax, R. Delewi, M. Meuwissen, J.P.S. Henriques, J.J. Piek, The Doppler flow wire in acute myocardial infarction, Heart 96 (2010) 631-635, https://doi.org/10.1136/hrt.2009.186932

[174] E.J. Alles, R.J. Colchester, A.E. Desjardins, Adaptive light modulation for improved resolution and efficiency in all-optical pulse-echo ultrasound, IEEE Trans. Ultrason. Ferroelectr. Freq. Control. 63 (2016) 83-90, https://doi.org/10. 1109/TUFFC.2015.2497465

[175] I. Ocak, A. Kara, C. Ince, Monitoring microcirculation, Best. Pract. Res. Clin. Anaesthesiol. 30 (2016) 407-418, https://doi.org/10.1016/j.bpa.2016.10.008
[176] C. Lal, M.J. Leahy, An updated review of methods and advancements in microvascular blood flow imaging, Microcirculation 23 (2016) 345-363, https:// doi.org/10.1111/micc.12284

[177] X. Liu, Y. Huang, J.U. Kang, Dark-field illuminated reflectance fiber bundle endoscopic microscope, J. Biomed. Opt. 16 (2011) 046003, https://doi.org/10.1117 1.3560298

[178] E.C. Mackle, E. Maneas, C. Little, E. Carr, W. Xia, D. Nikitichev, R. Rakhit, M. Finlay, A. Desjardins, Wall-less vascular poly(vinyl) alcohol gel ultrasound imaging phantoms using 3D printed vessels, Des. Qual. Biomed. Technol. XII, SPIE, 2019, p. 25, https://doi.org/10.1117/12.2510033

[179] C.K. Ho, A.J.Y. Chee, G.S. Member, B.Y.S. Yiu, A.C.O. Tsang, K.W. Chow, A.C.H. Yu, S. Member, Wall-Less flow phantoms with tortuous vascular geometries: design principles and a patient-specific model fabrication example, IEEE Trans. Ultrason. Ferroelectr. Freq. Control. 64 (2017) 25-38, https://doi.org/10.1109/ TUFFC.2016.2636129

Eleanor C. Mackle graduated from the University College London (UCL) with a BSc in Natural Sciences, and holds an MRes in Medical Imaging \& Biomedical Engineering from the same institution. She is currently completing her PhD in Biomedical Engineering at the Wellcome/EPSRC Institute for Surgical and Interventional Sciences at UCL. Her main research interests include minimally invasive devices and phantom fabrication.

Joanna M. Coote received a BSc in Physics from Imperial College London in 2004, and a PhD from the University of Surrey in 2009. She is currently a Postdoctoral Research Associate at University College London, researching optical sensors for physiological monitoring in minimally invasive interventional procedures.

Elizabeth Carr received her MPhys degree in Physics at Oxford University, UK, in 2017 and an MRes from University College London (UCL) in 2018 as part of the Centre for Doctoral Training (CDT) of Medical Imaging. She is currently completing her Ph.D. within the Department of Medical Physics and Bioengineering at UCL, focusing on an all-optical flow sensor developed at UCL for the use of blood flow sensing.

Callum D. Little received MBBS and BSc degrees in Medicine from Imperial College London, United Kingdom. Currently he is a Ph.D. student in Medical Imaging at University College London, UK and a specialist trainee in Interventional Cardiology at the Hammersmith Hospital, London, UK. His research interests include the translation of novel intravascular imaging and physiology technologies into the clinical field of coronary intervention.

Gijs van Soest leads the research group "Invasive imaging", which investigates catheter-based imaging technologies, primarily aimed at guidance of cardiovascular interventions but with an eye to other applications (diagnostics, imaging in lung or gastrointestinal tract) as well. Van Soest is an experimental physicist by training (MSc Rijksuniversiteit Groningen 1997). He started working in optics and light scattering during his $\mathrm{PhD}$ (Universiteit van Amsterdam, 2001). He worked as a postdoc at the Royal Netherlands Meteorology Institute (KNMI) to investigate atmospheric ozone profiles using satellite-borne spectrometers. In 2005 he joined the Biomedical Engineering group of the Thorax Center at Erasmus MC. Starting a new research topic in optical imaging and taking on the existing research in intravascular ultrasound, he developed his own research line. He was appointed Full Professor in 2020.

Adrien E. Desjardins is a Professor of Biomedical Engineering at the University College London (UCL), where he leads the Interventional Devices group. He received the B.Sc. degree from The University of British Columbia, Vancouver, BC, Canada, in 2001 and the Ph.D. degree from Harvard Biophysics and the Harvard-MIT Health Sciences and Technology Program, Cambridge, MA, USA, in 2007. His research is centred on the development of new imaging and sensing modalities to guide minimally invasive medical procedures. 